\title{
Sub1 Rice: Engineering Rice for Climate Change
}

\author{
Kyle Emerick ${ }^{1}$ and Pamela C. Ronald ${ }^{2}$ \\ ${ }^{1}$ Department of Economics, Tufts University, Medford, Massachusetts 02155-6722 \\ ${ }^{2}$ Department of Plant Pathology, College of Agricultural and Environmental Sciences Genome Center, \\ University of California, Davis, California 95616 \\ Correspondence: pcronald@ucdavis.edu
}

By the year 2100, the number of people on Earth is expected to increase by $50 \%$, placing increasing demands on food production in a time when a changing climate is predicted to compromise crop yields. Feeding this future world requires scientifically informed innovations in agriculture. Here, we describe how a rice gene conferring tolerance to prolonged submergence has helped farmers in South and Southeast Asia mitigate rice crop failure during floods. We discuss how planting of this new variety benefited socially disadvantaged groups. This example indicates that investment in agricultural improvement can protect farmers from risks associated with a changing climate.

$\mathrm{R}^{\mathrm{i}}$ ice is the staple food for more than half of the world's population. In South and Southeast Asia, where the majority of the world's rice farmers live, flooding is a major limitation on yield. Although rice grows well in standing water, most varieties of rice will die if they are completely submerged for more than 3 days. Each year, 25\% of the global rice croplands are inundated by flash floods, which are unpredictable and can occur several times a year. Yield losses caused by flooding disproportionately affect the poorest farmers in the world, millions of whom live on less than $\$ 3$ a day.

The predicted effects of climate change will make rice production even more difficult in the coming years. Severe flooding is expected to become more frequent in many rice-producing parts of the world (Hirabayashi et al. 2013). As glaciers in the Himalayas melt, river systems will experience more intense seasonal flows, leading to increased flooding of low-lying croplands. Most of the coastal rice production areas in the tropics and subtropics are vulnerable, especially low-lying deltas along the coastlines of South, East, and Southeast Asia, such as the Mekong and Red River deltas of Vietnam, the Ayeyerwaddy delta of Myanmar, and the GangesBrahmaputra delta of Bangladesh. These deltas provide between $34 \%$ and $70 \%$ of the total rice production in these countries, and any reduction in rice production owing to increases in the frequency of flooding will have serious consequences for food security (Wassmann et al. 2009). In Bangladesh, Eastern India, Vietnam, and Myanmar, people get about two-thirds of their total calories from rice.

Thus, an important goal for improving the rural economy and livelihood in these vulnerable countries is to develop rice varieties that can survive flooding. Because most of the world's

Editor: Pamela C. Ronald

Additional Perspectives on Engineering Plants for Agriculture available at www.cshperspectives.org

Copyright (C) 2019 Cold Spring Harbor Laboratory Press; all rights reserved; doi: 10.1101/cshperspect.a034637

Cite this article as Cold Spring Harb Perspect Biol 2019;11:a034637 
poorest people get their food and income by farming small plots of land, the availability of rice varieties with enhanced tolerance to flooding is expected to make a major difference in food security for these farmers.

Unlike most commercially grown rice varieties, there are a few rice landraces that can survive prolonged submergence, and these are of great interest to rice breeders. For example, the ancient Indian rice landrace, Dhalputtia, has poor grain and yield qualities but is unusual in its ability to endure complete submergence for more than 14 days. The cultivar FR13A (Flood Resistance 13A) is a cultivar derived from the Dhalputtia landrace.

For more than 40 years, breeders at the International Rice Research Institute (IRRI) used FR13A and its progeny as donor parents to introduce the submergence tolerance into varieties grown by rice farmers. Because breeding was performed with relatively crude genetic tools based mainly on visual selection, the resulting varieties lacked many of the traits desired by farmers in the major rice-growing areas of Asia. Without knowledge of the exact genes needed to confer submergence tolerance, breeders unknowingly dragged in undesirable traits along with the submergence tolerance trait, which reduced yield and grain quality. For these reasons, the new varieties were not widely adopted.

Starting in the 1980 s, researchers began to characterize the genetic basis for the submergence tolerance trait in cultivar FR13A. The goal was to generate tools that breeders could use to develop rice varieties with high yields and good grain quality that are tolerant to submergence. The results of this team effort led to the identification of the Sub1 locus and associated genes, development of rice "mega varieties" with submergence tolerance for farmers, and elucidation of the gene networks and physiological processes mediated by $S u b 1$.

This review describes the research process that led to the development of submergencetolerant rice and the agronomic and socioeconomic impacts of the resulting varieties. We briefly review the technological advances that led to isolation of the Sub1A gene conferring submergence tolerance (Xu and Mackill 1996;
Xu et al. 2000, 2006) and describe its predicted mode of action (Fukao et al. 2006). Finally, we discuss field-based research on the adoption of submergence-tolerant rice and evaluate the impact that growing submergence-tolerant rice has had for smallholder farmers.

\section{MAKING A GENETIC MAP TO LOCALIZE THE SUBMERGENCE TOLERANCE GENES}

Early genetic studies showed that rice submergence tolerance derived from the landrace FR13A had a relatively high heritability, with tolerance being partially to completely dominant (Suprihatno and Coffman 1981; Mohanty et al. 1982; Mohanty and Khush 1985; Sinha and Saran 1988; Haque et al. 1989). The trait was thought to be controlled by one or a few loci with major effects and other loci with smaller, modifying effects. On the basis of these studies, breeder David Mackill and colleagues (University of California Davis; IRRI) began to investigate submergence tolerance using an approach combining the power of molecular markers and quantitative trait locus (QTL) analyses. This initial study used a population (DX18) of $169 \mathrm{~F}_{2}$ plants and their resulting $\mathrm{F}_{3}$ families. This population was derived from a cross between IR40931-26 (indica), which inherits submergence tolerance from FR13A, and a breeding line, PI613988 ( japonica; submergence intolerant). In 1996, Mackill and colleagues showed that a major QTL, Sub1, was located between two restriction fragment length polymorphism (RFLP) markers (C1232 and RZ698) on rice chromosome 9 (Xu and Mackill 1996). The Sub1 QTL was supported with a logarithm of odds (LOD) score of 36 and accounted for $69 \%$ of phenotypic variation in the $\mathrm{F}_{2}$ population, indicating that the Sub1 locus is critical for conferring submergence tolerance in rice. Simultaneously, other teams (Nandi et al. 1997; Kamolsukyunyong et al. 2001; Toojinda et al. 2003) also reported the strong phenotypic effect of the Sub1 locus, confirming its effect as the major determinant of tolerance in conjunction with a few other minor QTLs.

Based on these promising mapping experiments, the Ronald and Mackill laboratories 
launched a map-based cloning effort to isolate the $S u b 1$ gene. Previously, the Ronald laboratory had successfully used this approach to isolate the rice $\mathrm{Xa} 21$ gene, which confers broad-spectrum resistance to a serious bacterial disease in Asia and Africa (Song et al. 1995).

The team first performed fine mapping of the Sub1 QTL to characterize the Sub1 region in a large $F_{2}$ population of 2950 plants, which was derived from a cross between M202 (a widely grown japonica rice cultivar in California) and DX18-121 (a tolerant line derived from FR13A). The resulting Sub1 high-resolution map consisted of 10 amplified fragment length polymorphism (AFLP) markers. Two of these markers cosegregated with Sub1 and eight were linked to Sub1 within $0.2 \mathrm{cM}$ (Xu et al. 2000). This fine map laid the foundation for physically mapping the Sub1 locus on rice chromosome 9.

Subsequent physical mapping of the Sub1 locus led to the identification of five bacterial artificial chromosome (BAC) and 13 binary clones that overlapped each other and that entirely covered the Sub1 region (Xu et al. 2006). By developing more markers from these BAC and binary clones and analyzing an expanded $\mathrm{F}_{2}$ population of 4022 plants, Kenong $\mathrm{Xu}$ was able to delimit the Sub1 locus to a region of 182 $\mathrm{kb}$ between markers CR25K and SSR1A (Xu et al. 2006).

$\mathrm{Xu}$ and Ronald next performed complete sequencing of the 182-kb Sub1 region and identified 13 genes in the region, including three that encoded for proteins with ethylene responsefactor (ERF) domains, which showed similarity to known transcription factors. These genes were designated Sub1A-1, Sub1B, and Sub1C-1. The team found that the corresponding $S u b 1$ region in the sequenced genome of japonica rice Nipponbare (International Rice Genome Sequencing Project 2005), which is intolerant of submergence, spans only $142 \mathrm{~kb}$ and lacks Sub1A-1.

In collaboration with Mackill and colleagues at IRRI, $\mathrm{Xu}$ and Ronald next performed an allelic variation survey of the Subl genes in 21 additional rice varieties. They found that the Sub1A-1 and Sub1C-1 alleles were present in all six submergence-tolerant accessions studied, including FR13A, Goda Heenati, and Kurkurapan, but were lacking in the intolerant varieties. There was no correlation between the presence of a specific Sub1B allele and submergence tolerance.

Using gene expression analysis, $\mathrm{Xu}$ observed that $S u b 1 A-1$, but not $S u b 1 B$ or Sub1C-1, was rapidly induced on submergence in the submergence-tolerant variety. These data suggested that Sub1A-1 (referred to here as Sub1A) controlled the Sub1-mediated submergence tolerant response.

To functionally assess whether SublA conferred submergence tolerance, $\mathrm{Xu}$ and others in the Ronald laboratory created a construct containing the Sub1A full-length cDNA under the control of the maize Ubiquitin1 promoter (Christensen and Quail 1996) and overexpressed this construct in a submergence-intolerant japonica rice. Submergence screening of the resulting T1 transgenic plants identified four independent T1 families segregating for submergence. A detailed analysis of two of the four T1 families showed a complete correlation between high expression of the Sub1A transgene and submergence tolerance (Fig. 1), leading to the conclusion that $S u b 1 A$ is sufficient to confer submergence tolerance to an intolerant variety (Xu et al. 2006).

\section{MARKER-ASSISTED BREEDING AND FIELD ASSESSMENTS}

Initially, the IRRI group monitored the Sub1 locus using markers closely linked with the gene. However, the availability of the sequences from BAC clone AP005907, which carried the sequences of the Sub1 genes, soon facilitated the development of six more markers tightly linked to the Sub1 QTL. This approach allowed for the transfer of the "donor" (Sub1) genetic region to be precisely monitored. With knowledge of the precise location and sequence of Sub1A and the ability to select against other regions of the FR13A genome that potentially were associated with undesirable agronomic characteristics, the Sub1 locus could be precisely introduced into a wide range of recipient rice 
K. Emerick and P.C. Ronald

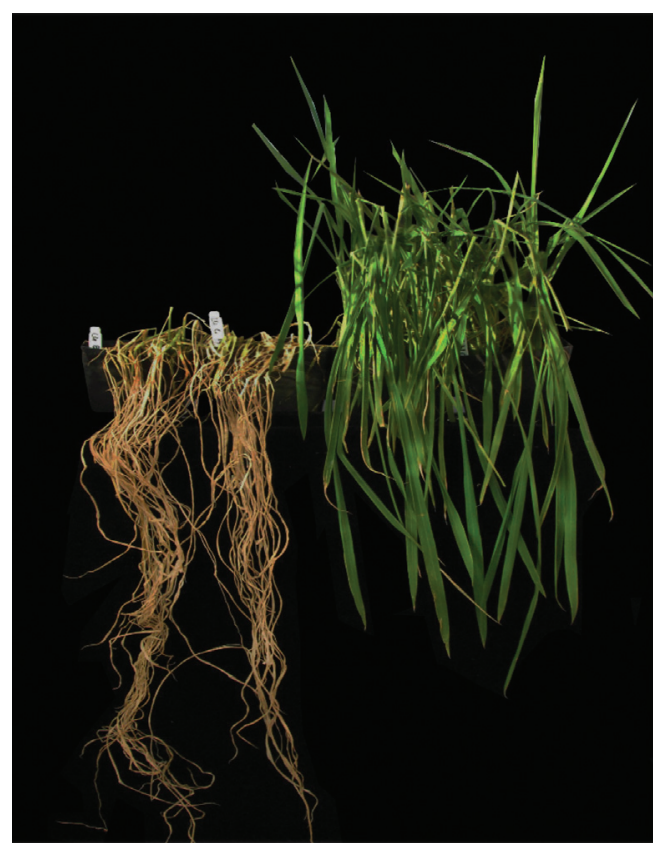

Figure 1. Expression of the Sub1A transgene (right) confers robust tolerance to submergence compared with the control rice $(l e f t)$. Plants were grown for 2 weeks, submerged for 2 weeks, and then allowed to recover for 2 weeks before photography (Ronald laboratory). This work was significant because it represented the first isolation of a quantitative trait locus (QTL) with an important agronomic effect. Isolation of Sub1A and the $180 \mathrm{~kb}$ of genetic sequence surrounding the gene set the stage for advanced marker-assisted breeding at the International Rice Research Institute (IRRI) (Neeraja et al. 2007; Septiningsih et al. 2009; Mackill et al. 2012).

varieties favored by farmers, while at the same time minimizing the effects of "linkage drag" from the Sub1 donor (Neeraja et al. 2007). This work resulted in the introduction of Sub1 into rice varieties popular in South and Southeast Asia. The first of these was the mega variety Swarna, which is grown on approximately five million hectares in India and on additional areas in Bangladesh and Nepal (Xu et al. 2006).

As described in an earlier review (Xu et al. 2013), the new rice variety-called SwarnaSub1-was tested in farmers' fields in Bangladesh and India. In the absence of flooding, both Swarna and Swarna-Sub1 yield 5 to 6 tons per hectare. However, in the presence of flooding, fewer plants of the Swarna rice crop survived ( $0 \%$ to $20 \%$ in most cases depending on floodwater conditions and duration; Das et al. 2009), whereas the Swarna-Sub1 rice flourished-80\% to $95 \%$ of it survived (Fig. 2). This enhanced survival means that farmers growing the Swarna-Sub1 variety gain 1 to $>3$ tons per hectare yield advantage compared with farmers growing the intolerant cultivars following floods (Singh et al. 2009). Using this marker-assisted breeding approach, the IRRI team also generated and released several additional Subl varieties in six countries (Indonesia, Nepal, Mynamar, India, Bangladesh, and Philippines).

Researchers at IRRI collaborated with national research systems, national and state governments, nongovernmental organizations (NGOs), and public and private seed producers and breeders to multiply and disseminate Swarna-Sub1 seeds and seeds of other Sub1 varieties. The Bill and Melinda Gates Foundation supported stress-tolerant rice for Africa and South Asia (STRASA), an IRRI program in collaboration with AfricaRice. STRASA has assisted with the development and dissemination of Sub1 rice and other rice varieties since 2007. In 2017 alone, more than six million farmers in India, Bangladesh, and Nepal grew Sub1 rice.

\section{WHAT IS THE MECHANISM OF SUb1A ACTION?}

The isolation of Sub1A paved the way for investigations into how Sub1A conferred the powerful and beneficial phenotypic effect: tolerance to submergence. As discussed above, the sequence of Sub1A indicated that it was similar to proteins that serve as transcription factors, which can regulate a large set of genes. Furthermore, the predicted Sub1A transcription factor, showed similarity to transcription factors activated by the plant hormone ethylene.

This observation was consistent with previous studies. In 1996, scientists reported that ethylene accumulates in response to submergence stress (Banga et al. 1996; Kende et al. 1998; Peng et al. 2001) and that this stress triggered synthesis of another important plant hormone called gibberellic acid (GA) known to induce 


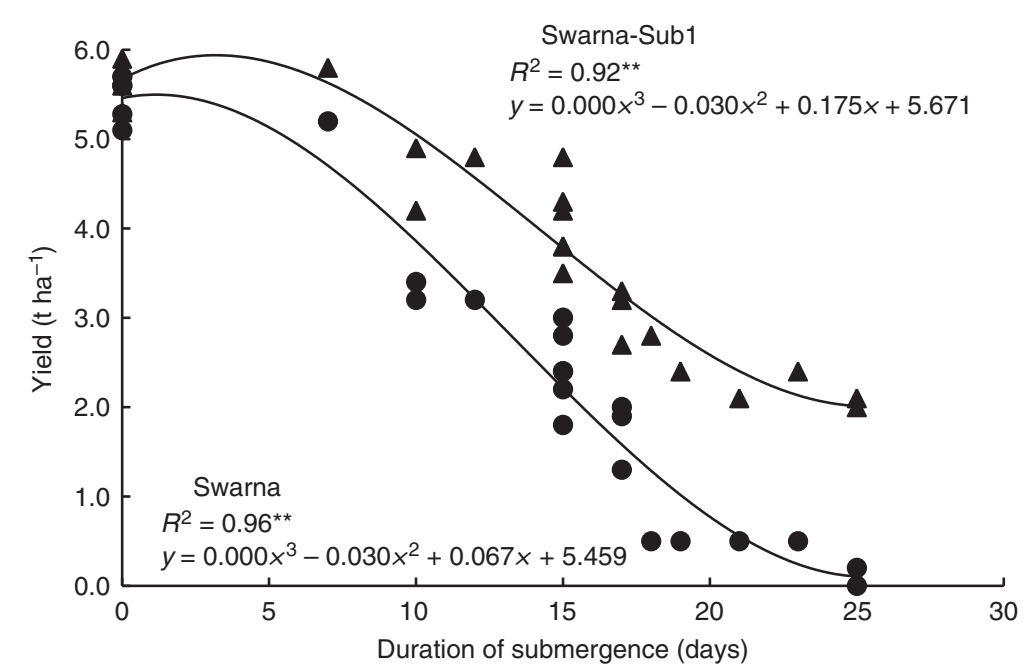

Figure 2. Yield of Swarna and Swarna-Sub1 under variable durations of submergence in farmers' fields. Data are from 24 farmers in Uttar Pradesh, India, during the wet season of 2007 who cultivated both varieties $(n=24)$. (From Ismail et al. 2013; reproduced, with permission, from Elsevier (c) 2013.)

shoot elongation (Kende et al. 1998; Peeters et al. 2002).

In 2006, experiments led by Julia BaileySerres and Takesh Fukao at the University of California, Riverside, showed that the presence of Sub1A represses GA synthesis and GA-mediated signaling pathways. This repression results in a reduction in shoot elongation. Thus, during a flood, when the plants are submerged, shoot elongation of Sub1 plants is reduced. BaileySerres and team further showed that Sub1A exerts its effect by reducing carbohydrate consumption, preventing chlorophyll breakdown, and activating alternative energy pathways. Thus, the Sub1A plants adopt a "hold your breath" strategy; they stop growing until the flood subsides, conserving energy needed for survival (Singh et al. 2001; Das et al. 2005).

\section{Adoption, Impact, and Diffusion of Sub1 Rice}

Research on Sub1 next focused on the adoption, impact, and diffusion of these rice varieties. Does Sub1 still confer its key benefits in the fields of resource-constrained farmers whose objectives (maximizing profits) may be very different from those of scientists in agronomic trials? Who benefits the most from Sub1? Are there unexpected benefits that result from making rice more flood tolerant?

Answering these questions required experimentation with Sub1 varieties in farmers' fields instead of in controlled research facilities. The initial introduction of Sub1 into farmer's fields focused on farmers that were known to IRRI scientists. Rigorously establishing impact in farmers' fields required testing new varieties with a broader population of farmers. Moreover, random assignment of Sub1 varieties to farmers was important to more fully characterize its impact on a diverse population of farmers. Starting in 2011, shortly after Swarna-Sub1 had been released in India by IRRI, Emerick and colleagues began a randomized controlled trial to evaluate the efficacy of Sub1 varieties that were distributed to a broad group of smallholder farmers. For this purpose, researchers randomly divided 128 villages (Fig. 3 ) across two districts in the state of Odisha into two groups: a treatment group in which five farmers were provided with $5 \mathrm{~kg}$ of Swarna-Sub1 seed and a control group in which farmers continued to grow their chosen varieties - most often Swarna (Dar et al. 2013).

This investigation confirmed earlier results (Ismail et al. 2013) that Swarna-Sub1 delivers 
K. Emerick and P.C. Ronald

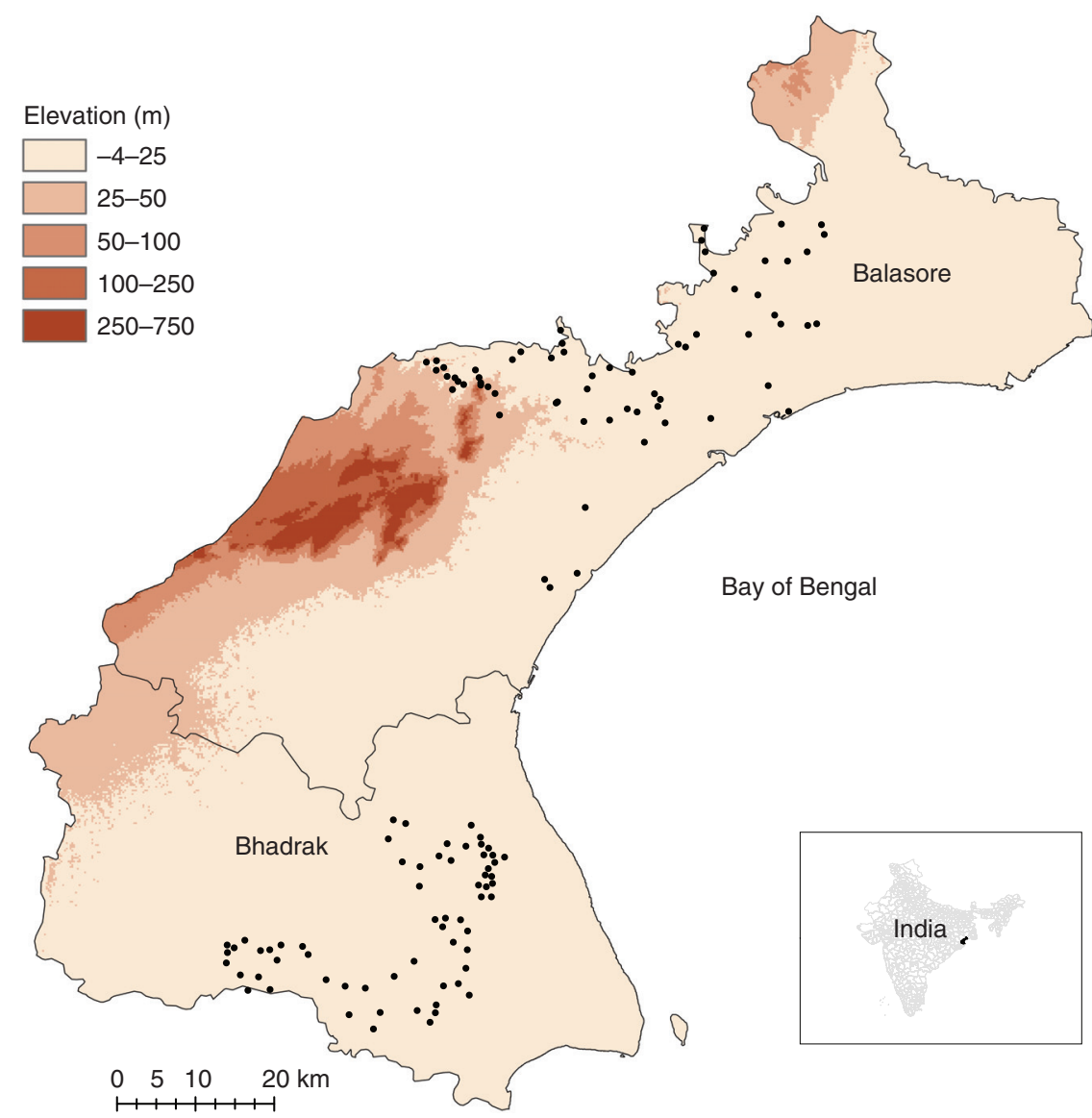

Figure 3. Map of the 128 villages where the Swarna-Sub1 randomized controlled trial was performed in the 2011 and 2012 Kharif rainy seasons. (From Emerick et al. 2016; reproduced, with permission, from the authors.)

yield advantages to farmers during flooding, and does not affect yield under nonflood conditions. Heavy flooding affected coastal parts of Odisha in September 2011. This event resulted in differential flood exposure for the 128 villages in the study. The fields grown with Swarna-Sub1, but not affected by flooding, produced rice yields similar to that of Swarna (Fig. 4). In contrast, relative to Swarna, Swarna-Sub1 had 45\% higher yields on fields that were flooded for 10 days. In other words, the previously observed higher yield of Swarna-Sub1 during flooding shown in initial field tests by the IRRI team were confirmed for a broader set of farmers (Dar et al. 2013).

The next step was to better understand who would benefit from diffusion of Swarna-Sub1.
Using satellite data on flooding and geo-referenced census data, Dar et al. (2013) found that flooded areas were more heavily occupied by lower caste farmers. These farmers are economically and socially disadvantaged according to a number of metrics, including education, income, and consumption. Taken together, Dar et al. (2013) provided evidence that Swarna-Sub1, by lessening the damage from heavy flooding, delivered the highest impacts for the most marginalized segments of the farming population.

In addition to this biological mechanism (higher yields), there is an economic mechanism through which Sub1 rice can improve outcomes for farmers. The 2012 wet season-the second year of the experiment-was not a flood year in Odisha. Yet, farmers randomly introduced to 


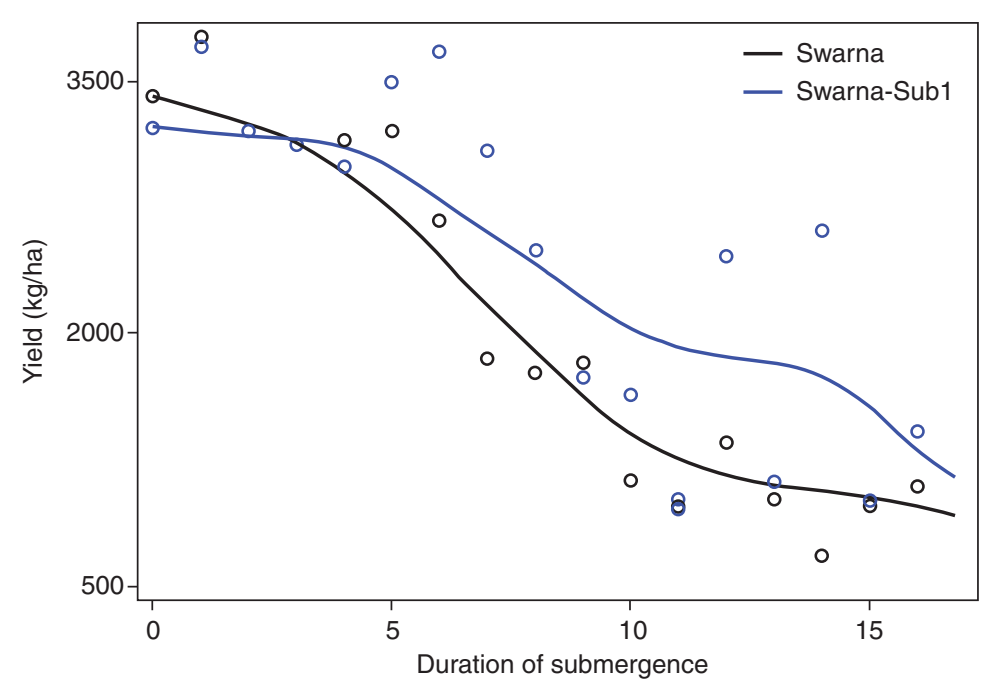

Figure 4. Experimental evidence on the flood tolerance of Swarna-Sub1. The horizontal axis shows the duration the plot was submerged during the season (in days). The vertical axis shows the yield in kilograms per hectare. The blue and black lines show nonparametric Fan regressions of yield on flooding duration. The blue line is for the Swarna-Sub1 treatment group, whereas the black line is for the control group. The dots show the average yields for different flood durations for Swarna-Sub1 (blue) and Swarna (black). (Image created with data from Dar et al. 2013.)

Swarna-Sub1 before the 2011 season had 10\% higher rice yields in 2012, even in the absence of flooding (Emerick et al. 2016). How can this finding coexist with the established agronomic evidence that Swarna-Sub1 yields the same as Swarna under normal conditions? In short, planting Swarna-Sub1 reduces downside risk for the farmer, that is, the likelihood of a really bad harvest. By reducing this risk, introducing Swarna-Sub1 made farmers more comfortable in investing in their fields early in the season. Emerick et al. (2016) show that farmers introduced to Swarna-Sub1 used more fertilizer, were more likely to engage in a labor-intensive planting method, and cultivated more area (Fig. 5). Overall, the findings suggest that $>40 \%$ of the yield gains from Swarna-Sub1 arise from increased investment in their farms. Measuring these benefits required experimentation in the real-world scenario in which researchers could observe the effect of Sub1 technology on the profit-maximizing decisions of farmers.

With regard to diffusion, the data indicate that $S u b 1$ varieties are being adopted in floodprone areas of Bangladesh (Kretzschmar et al.
2018). IRRI has partnered with state and local governments to target the dissemination of Swarna-Sub1 in India to the most flood-prone areas. Using remote sensing observations of past flooding, IRRI has identified key target areas for dissemination and provided this information to state governments. The initial strategy for diffusion was to distribute minikits (a small package of seeds) at no cost to a small number of farmers in each village and then rely on diffusion through informal farmer-to-farmer seed trading networks.

The data show this approach of providing seed through diffusion has limitations. Emerick (2018) showed that farmers are willing to pay market prices for Swarna-Sub1, but are not always able to obtain the seeds from neighbors under informal seed trading, in which farmers trade seeds for seeds of another variety. Specifically, in 2013 Swarna was available to farmers in the Indian state of Odisha for a price of 12.5 rupees $/ \mathrm{kg}$. Farmers predominantly obtain new Swarna seeds from government supply centers to benefit from generous subsidies. In experiments led by Emerick (2018), public meetings 
K. Emerick and P.C. Ronald

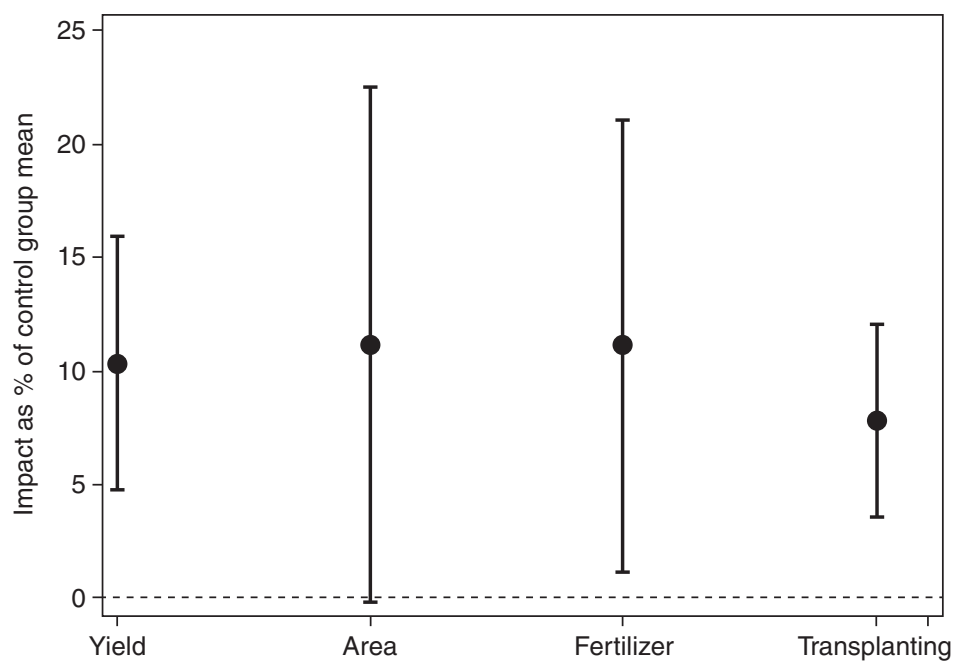

Figure 5. Percentage impact of introducing Swarna-Sub1 on the listed outcomes (dots). The black bands show the 95\% confidence intervals. The figure shows that Swarna-Sub1 farmers obtained higher yields, increased cultivated area, used more fertilizer (conditional on area), and were more likely to transplant their fields. All these effects occurred in a year without flooding. (Image based on authors' calculations using the replication data in Emerick et al. 2016.)

were held during the 2012 season to educate farmers on the benefits of Swarna-Sub1. Five farmers in each of 82 villages were then provided Swarna-Sub1 seed, free of cost. The villages were then divided into two groups. In the first group of 41 villages, farmers could only obtain seeds by trading seeds of another variety with the five farmers who had received and grown the Swarna-Sub1 seeds. In the second group of 41 villages, 15 different farmers were given the opportunity to purchase Swarna-Sub1 seeds directly from an NGO at different prices. The NGO did not provide any new information about Swarna-Sub-only the same information provided at the original public meeting. Data reveal that the system of informal farmer-to-farmer trading (the first group of villages in this study) results in only $7 \%$ adoption of SwarnaSub1, whereas a much higher percent of farmers (35\% at a price point of 14 rupees $/ \mathrm{kg}$, and $41 \%$ at a price of 12 rupees $/ \mathrm{kg}$ in the second group of villages in this study) were willing to pay for the variety through door-to-door sales (Emerick 2018). In sum, relying on informal diffusion between farmers prevents Swarna-Sub1 from reaching farmers that are willing to pay for the variety. Emerick (2018) provides evidence for one possible explanation of the data: informal trading limits seed transfers to farmers within well-defined social networks, such as caste groups. Ongoing work is therefore needed to test new ways to introduce $S u b 1$ varieties to generate broader diffusion that will increase the rate of diffusion outside these limited social networks. For instance, making seeds locally available for purchase, and thus eliminating the need to rely on seed exchange with other farmers, would likely result in more widespread adoption.

\section{CONCLUDING REMARKS}

It is estimated that an additional 116 million tons of rice will be needed by 2035 to feed the growing population (Seck et al. 2012). Herein, we have reviewed the scientific advances that led to the identification of the SublA gene, which confers submergence tolerance to rice, and the subsequent diffusion and adoption of flood-tolerant Swarna-Sub1 rice to farmers in South and South East Asia. In addition to flooding, other environmental stresses such as drought, salinity, and heat stress are predicted to be increasingly 
problematic for farmers as the climate warms. Thus, as has been performed for Sub1, there is a need to identify genes that confer robust tolerance to environmental stresses and to use this information to develop new varieties of rice and other staple crops.

The research on Sub1 also shows the complementarity between research in genetics, agronomy, and the social sciences. Identifying genes, developing new varieties, and assessing their performance in field trials is the fundamental starting point. Social scientists are needed to evaluate the overall economic impacts of newly developed varieties and technologies. In many cases, the availability of new varieties changes the investment strategies of farmers. For instance, it may prompt farmers to cultivate more farmland or use more fertilizer-both responses that could further affect profitability. Once these behaviors are understood, there may be room for complementary policies that make these adjustments easier. For example, enhancing access to land that can be rented on fair terms would allow farmers to expand cultivation. Additionally, farmers may need access to credit to increase their fertilizer use. Overall, these results highlight the value of rigorous and randomized field experimentation to adequately assess the overall economic impacts of new varieties. Our research also indicates the need for additional research to inform policies that will speed the diffusion of these new and beneficial varieties.

\section{REFERENCES}

Banga M, Slaa EJ, Blom C, Voesenek L. 1996. Ethylene biosynthesis and accumulation under drained and submerged conditions (A comparative study of two Rumex species). Plant Physiol 112: 229-237. doi:10.1104/pp.112 .1 .229

Christensen AH, Quail PH. 1996. Ubiquitin promoter-based vectors for high-level expression of selectable and/or screenable marker genes in monocotyledonous plants. Transgenic Res 5: 213-218. doi:10.1007/BF01969712

Dar MH, De Janvry A, Emerick K, Raitzer D, Sadoulet E. 2013. Flood-tolerant rice reduces yield variability and raises expected yield, differentially benefitting socially disadvantaged groups. Sci Rep 3: 3315. doi:10.1038/ srep03315

Das KK, Sarkar RK, Ismail AM. 2005. Elongation ability and non-structural carbohydrate levels in relation to submer- gence tolerance in rice. Plant Sci 168: 131-136. doi:10 .1016/j.plantsci.2004.07.023

Das KK, Panda D, Sarkar RK, Reddy JN, Ismail AM. 2009. Submergence tolerance in relation to variable floodwater conditions in rice. Environ Exp Bot 66: 425-434. doi:10 .1016/j.envexpbot.2009.02.015

Emerick K. 2018. Trading frictions in Indian village economies. J Dev Econ 132: 32-56. doi:10.1016/j.jdeveco.2017 .12 .010

Emerick K, De Janvry A, Sadoulet E, Dar MH. 2016. Technological innovations, downside risk, and the modernization of agriculture. Am Econ Rev 106: 1537-1561. doi:10.1257/aer.20150474

Fukao T, Xu K, Ronald PC, Bailey-Serres J. 2006. A variable cluster of ethylene response factor-like genes regulates metabolic and developmental acclimation responses to submergence in rice. Plant Cell 18: 2021-2034. doi:10 $.1105 /$ tpc.106.043000

Haque QA, Hille Ris Lambers D, Tepora NM, dela Cruz QD. 1989. Inheritance of submergence tolerance in rice. Euphytica 41: 247-251. doi:10.1007/bf00021591

Hirabayashi Y, Mahendran R, Koirala S, Konoshima L, Yamazaki D, Watanabe S, Kim H, Kanae S. 2013. Globa flood risk under climate change. Nat Clim Chang 3: 816-821. doi:10.1038/nclimate1911

International Rice Genome Sequencing Project. 2005. The map-based sequence of the rice genome. Nature 436: 793-800. doi:10.1038/nature03895

Ismail AM, Singh US, Singh S, Dar MH, Mackill DJ. 2013. The contribution of submergence-tolerant (Sub1) rice varieties to food security in flood-prone rainfed lowland areas in Asia. Field Crops Res 152: 83-93. doi:10.1016/j.fcr .2013.01.007

Kamolsukyunyong W, Ruanjaichon V, Siangliw M, Kawasaki S, Sasaki T, Vanavichit A, Tragoonrung S. 2001. Mapping of quantitative trait locus related to submergence tolerance in rice with aid of chromosome walking. DNA Res 8: 163-171. doi:10.1093/dnares/8.4.163

Kende H, van der Knaap EE, Cho H-T. 1998. Deepwater rice: A model plant to study stem elongation. Plant Physiol 118: 1105-1110. doi:10.1104/pp.118.4.1105

Kretzschmar T, Mbanjo EGN, Magalit GA, Dwiyanti MS, Habib MA, Diaz MG, Hernandez J, Huelgas Z, Malabayabas ML, Das SK, et al. 2018. DNA fingerprinting at farm level maps rice biodiversity across Bangladesh and reveals regional varietal preferences. Sci Rep 8: 14920. doi:10 .1038/s41598-018-33080-z

Mackill DJ, Ismail AM, Singh US, Labios R V., Paris TR. 2012. Development and rapid adoption of submergence-tolerant (Sub1) rice varieties. Adv Agron 115: 299-352. doi:10.1016/B978-0-12-394276-0.00006-8

Mohanty HK, Khush GS. 1985. Diallel analysis of submergence tolerance in rice, Oryza sativa L. Theor Appl Genet 70: 467-473. doi:10.1007/BF00305978

Mohanty HK, Suprihatno B, Khush GS, Coffman WR, Vergara BS. 1982. Inheritance of submergence tolerance in deepwater rice. In Proceedings of the 1981 International Deepwater Rice Workshop, pp. 121-133. Los Banos, Laguna, Philippines.

Nandi S, Subudhi PK, Senadhira D, Manigbas NL, SenMandi S, Huang N. 1997. Mapping QTLs for submer- 
K. Emerick and P.C. Ronald

gence tolerance in rice by AFLP analysis and selective genotyping. Mol Gen Genet 255: 1-8. doi:10.1007/ s004380050468

Neeraja CN, Maghirang-Rodriguez R, Pamplona A, Heuer S, Collard BCY, Septiningsih EM, Vergara G, Sanchez D, Xu K, Ismail AM, et al. 2007. A marker-assisted backcross approach for developing submergence-tolerant rice cultivars. Theor Appl Genet 115: 767-776. doi:10.1007/ s00122-007-0607-0

Peeters AJM, Cox MCH, Benschop JJ, Vreeburg RAM, Bou J, Voesenek LACJ. 2002. Submergence research using Rumex palustris as a model; looking back and going forward. J Exp Bot 53: 391-398. doi:10.1093/jexbot/53 .368 .391

Peng HP, Chan CS, Shih MC, Yang SF. 2001. Signaling events in the hypoxic induction of alcohol dehydrogenase gene in Arabidopsis. Plant Physiol 126: 742-749. doi:10 $.1104 /$ pp.126.2.742

Seck PA, Diagne A, Mohanty S, Wopereis MCS. 2012. Crops that feed the world 7: Rice. Food Secur 4: 7-24. doi:10 .1007/s12571-012-0168-1

Septiningsih EM, Pamplona AM, Sanchez DL, Neeraja CN, Vergara GV, Heuer S, Ismail AM, Mackill DJ. 2009. Development of submergence-tolerant rice cultivars: The Sub1 locus and beyond. Ann Bot 103: 151-160. doi:10 $.1093 / \mathrm{aob} / \mathrm{mcn} 206$

Singh HP, Singh BB, Ram PC. 2001. Submergence tolerance of rainfed lowland rice: Search for physiological marker traits. J Plant Physiol 158: 883-889. doi:10.1078/01761617-00036

Singh S, Mackill DJ, Ismail AM. 2009. Responses of SUB1 rice introgression lines to submergence in the field: Yield and grain quality. Field Crops Res 113: 12-23. doi:10 .1016/j.fcr.2009.04.003
Sinha MM, Saran S. 1988. Inheritance of submergence tolerance in lowland rice. Oryza 25: 351-354.

Song WY, Wang GL, Chen LL, Kim HS, Pi LY, Holsten T, Gardner J, Wang B, Zhai WX, Zhu LH, et al. 1995. A receptor kinase-like protein encoded by the rice disease resistance gene, Xa21. Science 270: 1804-1806. doi:10 $.1126 /$ science.270.5243.1804

Suprihatno B, Coffman WR. 1981. Inheritance of submergence tolerance in rice (Oryza sativa L.). SABRAO J Breed Genet 13: 98-108.

Toojinda T, Siangliw M, Tragoonrung S, Vanavichit A. 2003. Molecular genetics of submergence tolerance in rice: QTL analysis of key traits. Ann Bot 91: 243-253. doi:10.1093/ $\mathrm{aob} / \mathrm{mcf072}$

Wassmann R, Jagadish SVK, Sumfleth K, Pathak H, Howell G, Ismail A, Serraj R, Redona E, Singh RK, Heuer S. 2009. Regional vulnerability of climate change impacts on Asian rice production and scope for adaptation. $A d v$ Agron 102: 91-133. doi:10.1016/S0065-2113(09)01003-7

$\mathrm{Xu}$ K, Mackill DJ. 1996. A major locus for submergence tolerance mapped on rice chromosome 9. Mol Breed 2: 219-224. doi:10.1007/BF00564199

Xu K, Xu X, Ronald PC, Mackill DJ. 2000. A high-resolution linkage map of the vicinity of the rice submergence tolerance locus Sub1. Mol Gen Genet 263: 681-689. doi:10 $.1007 / \mathrm{s} 004380051217$

Xu K, Xu X, Fukao T, Canlas P, Maghirang-Rodriguez R, Heuer S, Ismail AM, Bailey-Serres J, Ronald PC, Mackill DJ. 2006. Sub1A is an ethylene-response-factor-like gene that confers submergence tolerance to rice. Nature $\mathbf{4 4 2}$ : 705-708. doi:10.1038/nature04920

$\mathrm{Xu}$ K, Ismail AM, Ronald PC. 2013. Flood tolerance mediated by the rice Sub1A transcription factor. In Plant abiotic stress (ed. Jenks MA, Hasegawa PM), pp. 1-14. Wiley, Oxford, UK. 


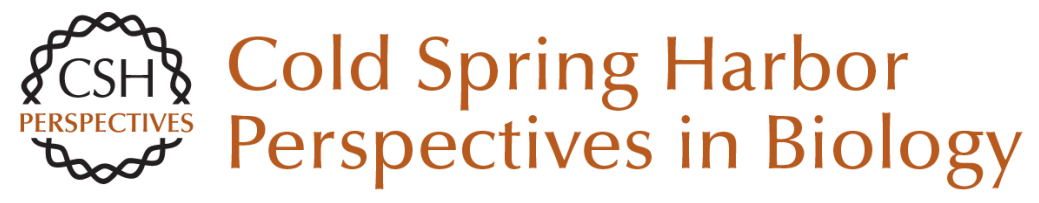

\section{Sub1 Rice: Engineering Rice for Climate Change}

Kyle Emerick and Pamela C. Ronald

Cold Spring Harb Perspect Biol 2019; doi: 10.1101/cshperspect.a034637 originally published online June 10, 2019

\section{Subject Collection Engineering Plants for Agriculture}

Plant Inflorescence Architecture: The Formation, Activity, and Fate of Axillary Meristems Yang Zhu and Doris Wagner

Sub1 Rice: Engineering Rice for Climate Change Kyle Emerick and Pamela C. Ronald

Engineering Disease-Resistant Cassava Z.J. Daniel Lin, Nigel J. Taylor and Rebecca Bart

Many Facets of Dynamic Plasticity in Plants Xiaodong Yang and Sally A. Mackenzie

How Do Strigolactones Ameliorate Nutrient Deficiencies in Plants?

Kaori Yoneyama

Mechanisms and Impact of Symbiotic Phosphate Acquisition Chai Hao Chiu and Uta Paszkowski
The Sweet Side of Plant-Specialized Metabolism Thomas Louveau and Anne Osbourn

The Role of Dwarfing Traits in Historical and Modern Agriculture with a Focus on Rice Ángel Ferrero-Serrano, Christian Cantos and Sarah M. Assmann

Bt Brinjal in Bangladesh: The First Genetically Engineered Food Crop in a Developing Country Anthony M. Shelton, Md. J. Hossain, Vijay Paranjape, et al.

Circadian Rhythms in Plants Nicky Creux and Stacey Harmer

Developing Blight-Tolerant American Chestnut Trees William A. Powell, Andrew E. Newhouse and Vernon Coffey

Stomatal Development and Perspectives toward Agricultural Improvement Hitoshi Endo and Keiko U. Torii

For additional articles in this collection, see http://cshperspectives.cshlp.org/cgi/collection/

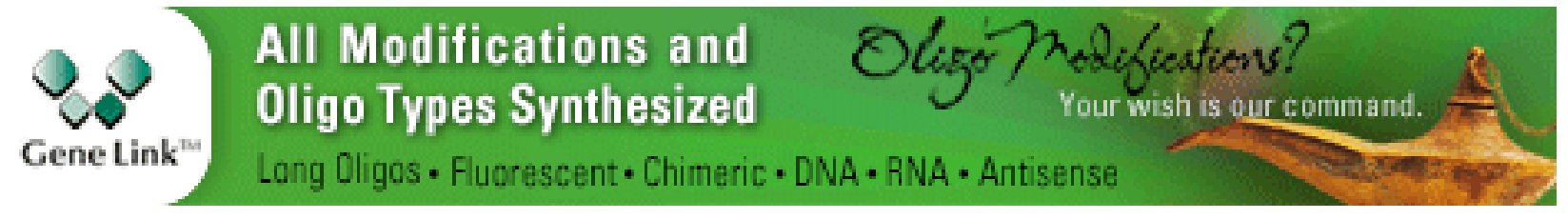

